\title{
The Educational Impact of Clothing Construction in Secondary and Post-Secondary Curriculum
}

\author{
Kelley C Coffeen* and Sharon J Bartley \\ Family and Consumer Science Department, New Mexico State University, USA
}

*Corresponding author: Kelley C Coffeen, Assistant Professor, Clothing, Textiles \& Fashion Merchandising, Department of Family \& Consumer Sciences, New Mexico State University, USA.

Received Date: July 01, 2020

Published Date: July 23, 2020

\begin{abstract}
Clothing construction knowledge, a foundational skill taught in Family and Consumer Sciences secondary and post-secondary classes, is being threatened at the middle and secondary levels as programs are dropped from curricula and classes are not offered. The decline in programs appears to be the result of a perceived negative value for clothing construction classes coupled with a misconception of career opportunities available to students in the fashion industry. This article discusses the career opportunities for students with clothing construction knowledge and skills in the robust and growing fashion industry, and suggests that a renewed focus on clothing construction skills and knowledge is vital to student success and career preparation for both family and consumer science education, and fashion merchandising and design students at the post-secondary level.

An online survey conducted with secondary and middle school Family and Consumer Sciences teachers; fashion industry professionals and college students majoring in Family and Consumer Sciences Education and Fashion Merchandising and Design determined the lived experiences and the importance of clothing construction in careers of Family and Consumer Sciences Education as well as Fashion Merchandising and Design students. A discussion of the benefits is included as well as the need for more research to support the continuance of clothing construction curricula in secondary and post-secondary Family and Consumer Sciences programs [1].
\end{abstract}

\section{Introduction}

The career opportunities in the fashion industry are diverse and expansive with fashion-related skills increasing in demand nationwide. Fashion is a $\$ 2.5$ trillion industry globally; in the U.S., fashion sales in apparel and footwear neared \$380 billion in 2017 [2]. Although fashion careers have historically been located in the fashion capitals of New York City and Los Angeles, jobs and careers in the fashion industry are now developing across the country, with design, retail, and marketing clusters appearing in the West and the South [3]. The majority of fashion and apparel jobs are in the retail sector, with over 1.4 million people working in retail establishments around the country, but a knowledge of clothing construction is needed across all segments of the industry.
A working knowledge and understanding of clothing construction and textiles are critical to the professional success of students entering the design, production, and merchandising areas of the fashion industry. Understanding the elements and principles in constructing and altering garments also helps prepare students for these robust career fields.

Middle and secondary Family and Consumer Sciences (FCS) programs traditionally included clothing construction classes in their curriculum. However, a decline in funding at the middle and secondary levels coupled with a shift in curriculum emphasis led to clothing construction classes being eliminated. Conversations with FCS teachers and local public-school administrators indicate 
a negative perceived value for clothing construction classes and a misconception of career opportunities available to students in the fashion industry.

At the post-secondary level, educators are increasingly concerned that students lack the basic construction skills needed to achieve optimal success in fashion and design classes. FCS education students are also stymied by a lack of basic construction skills and fear their required fashion and design classes.

Additionally, conversations with industry professionals indicate entry-level candidates lack the basic clothing construction skills/knowledge that they would deem necessary for success in the fashion industry.

Students in our fashion program at New Mexico State University, a Hispanic Serving Institution (HSI), tend to struggle with collegelevel clothing construction classes. Today's college class includes students with widely varying levels of skill/knowledge in clothing construction, with most students lacking the beginning clothing construction skills that were previously learned in middle and secondary FCS clothing classes. Students who lack rudimentary skills negatively impact the pace of the course as the learning process is slowed because of the necessity to include remedial content that should have been learned at the secondary level.

Based on conversations with our students, we became concerned about their lack of clothing construction knowledge, skills and confidence in this area. The purpose of this article is to add to the literature on this subject, and to begin a discussion about the impact of clothing construction taught in FCS secondary classes on fashion design and merchandising majors and Family and Consumer Science Education (FCSE) majors at the postsecondary level. Additionally, we included FCS secondary teachers and industry partners in order to garner a rich discussion with all possible stakeholders.

Historically, clothing construction was a fundamental part of the home economics curriculum that was conceptualized and created in the late 19th century to provide women with opportunities to earn degrees in higher education. Those women were expected to teach in public universities or schools and provide other women with training in the management of the home and family. The field of home economics has evolved with societal needs into what is now known as Family and Consumer Sciences (FCS). FCS programs continue to prepare students at the secondary and post-secondary levels for the varied careers associated with the field which includes fashion merchandising and design.

A review of the literature reveals a paucity of research on the benefits of clothing construction in university curriculum. Ward D, et al. [4] wrote that their review of the academic research about clothing construction and its impact on students pursuing careers in fashion industry did not find conclusive evidence concerning value of sewing skills for fashion merchandising majors. However,
Brandes $\mathrm{K}$, et al. [5] indicate that the biggest changes and growth in career opportunities within the apparel industry are occurring in the areas of computer-aided design, pattern making, product development and quality assurance. They reported that the desire for these skills in the industry is happening at the same time that high schools and universities have been reducing or eliminating programs that provide the basic skills in garment construction. Brandes $\mathrm{K}$, et al. [5] note that basic skills in garment construction are the foundation for those students who wish to enter apparelrelated careers. Additionally, the decline in the number of high school clothing construction courses has resulted in an increasing number of students entering university programs with inadequate understanding of basic clothing construction and textiles [5].

Another more recent article discussed whether college curriculums in fashion are meeting the needs of the apparel industry. The authors' findings indicated that the leading cause for lack of success of entry-level designers was the lack of fundamental skills in clothing construction, including basic knowledge of stitches and seam types [6]. Ma YJ, et al. [7] asked college students about their opinions on what information is critical for their success. Their findings indicated that the students felt that knowledge of basic clothing construction and the terminology associated with clothing were the most important knowledge/skills for clothing design and merchandising majors.

Clothing construction is taught in the middle and secondary schools by FCS teachers. The National Standards for Family and Consumer Sciences Education (NASAFACS 2018-2028) [8] guides curriculum development for secondary education and provides 16 content standards for the comprehensive field of Family and Consumer Sciences (FCS). One content standard pertains to textiles, fashion, and clothing. This content standard includes seven comprehensive standards for textiles, fashion and apparel. Of those seven comprehensive standards comprised of 42 substandard, only two sub standards concern skills related to clothing construction (FCS National Standards, NASAFACS 2018). Some authors, such as Ward, et al. [4] suggest that clothing construction skills have become less important due to changes in the work of the family and entry requirements for careers in the fashion and textile industry. Universities have reduced and/or eliminated their clothing construction classes due to expensive of equipment, labs, and their maintenance (Brandes \& Garner, 1997). FCSE students are also mandated to be proficient in clothing construction, since they are certified to teach those skills in their classes. However, FCSE students, like fashion students, tend to feel that they lack the necessary expertise in clothing construction to teach clothing construction, although it is one of their job [4]. Most recently, Martindale A, et al. [9] provided research on women's motivation to sew clothing for themselves and included a nice review of the literature for those interested in the evolution of home sewing including its resurgence. 


\section{Methods}

Four questionnaires were developed for the following populations: secondary and middle school Family and Consumer Sciences (FCS) teachers in New Mexico; Fashion Merchandising and Design (FMAD) students at New Mexico State University (NMSU); Family and Consumer Sciences Education (FCSE) students at NMSU; and fashion industry professionals.

The questionnaires developed by the researchers (FMAD and FCSE professors) included closed and open-ended questions. The questionnaire developed for FCS teachers included nine questions. The questionnaire developed for FMAD and FCSE students had five questions. The questionnaire developed for fashion industry professionals included four questions.

Survey instruments are available upon request from the researchers.

\section{Procedures}

The survey instrument designed for teachers was emailed to secondary and middle school FCS teachers in New Mexico from an email list provided by the New Mexico CTLP state office. The survey instrument designed for fashion students was emailed to 59 students currently enrolled in FMAD at NMSU. The survey instrument designed for FCSE students was emailed to 9 students at NMSU. In addition, the surveys were emailed to 13 industry professionals. Since participation was limited to the individuals willing to participate from those groups, the findings may not be representative of all secondary and middle school FCS teachers, college students enrolled in fashion merchandising, college students enrolled in family and consumer sciences education, and fashion industry professionals. A total of 14 useable surveys were obtained. Participants included five FCS teachers, three FCSE students, four FMAD students, and 3 industry professionals.

\section{Participants \& Sample}

The target populations in this study were selected to participate because of their impact on clothing construction classes offered at the university level: secondary and middle school Family and Consumer Sciences (FCS) teachers in New Mexico; Family and Consumer Sciences Education (FCSE) students enrolled at New Mexico State University (NMSU); Fashion Merchandising and Design (FMAD) students enrolled at NMSU; and fashion industry professionals.

The target populations were questioned about their experiences, knowledge of, and feelings regarding instruction in clothing construction at the secondary and college level of education and career success.

The five educators self-selected to participate in the survey. A series of nine questions were presented to FCSE secondary teachers. Questions were designed to determine teachers' perceived challenges and benefits of clothing construction classes, reasons clothing construction classes were/were not offered, the perceived importance of clothing construction classes, and students' interests in fashion-related careers.

Family and Consumer Sciences Education (FCSE) students at NMSU are all required to take clothing construction classes to fulfill National Standards and teacher licensure requirements at the national and state level. Three current FCSE students self-selected to participate in this study. These students responded to five questions. Questions were designed to determine the availability of clothing construction classes at their home high schools, other clothing construction experiences prior to their enrollment at NMSU, how those experiences impacted their experience in FMAD classes required in their program of study, and the importance of clothing construction knowledge for a fashion career.

Fashion Merchandising and Design (FMAD) students at NMSU are all required to take clothing construction classes to fulfill their degree requirements. Four students self-selected to participate in this study. They responded to five specific questions to determine the availability of clothing construction classes at their home high schools, how that experience impact them at the college level, and their opinions on the importance of clothing construction knowledge for their careers in the fashion industry.

Industry Professionals were included in this study to ascertain their opinions on the importance of clothing constructions knowledge and experience among employees for their businesses. Three industry professionals self-selected to participate in this study. These participants responded to four questions. Questions were designed to determine the importance of skills and knowledge of clothing construction in hiring employees for their companies. Factors include preference of candidates with clothing construction knowledge/skills, along with the task of finding candidates with clothing construction skills/knowledge.

\section{Data collection procedures and data analysis}

An online survey was administered to the convenience sample of FMAD and FCSE students at NMSU who self-selected to participate. Industry professionals and FCS teachers also selfselected to take survey. After responses were received, the authors used the responses to develop an overview of the participants' impressions and beliefs in the impact of clothing construction classes in middle and secondary schools on their ability to succeed in as professionals in Family and Consumer Science Education and the fashion industry.

\section{Findings}

FCSE educators at the secondary level who responded to the questionnaire provided the following information. Four of the five participants indicated that clothing construction was part of the curriculum in their school district, and they (or another teacher in their department) currently taught classes in clothing construction. Two of the five participants stated that clothing construction did 
not have a career pathway for students and contributed to the failure for school districts to either offer clothing construction classes and/or have students consider the classes when developing schedules. Two of the FCS teachers noted that clothing construction was a necessary life skill. Two other teachers stated that clothing construction skills are closely aligned with the Common Core Math standards, an added bonus for Career and Technical Education (CTE) teachers as many districts require CTE programs to reinforce common core content though their courses. One of the FCS teachers noted that her students had increased confidence levels due to their accomplishments of clothing construction skills.

The challenges associated with teaching clothing construction in secondary classrooms are significant. Teachers responded that challenges include the high financial costs for students associated with construction, including patterns, fabric, thread, and notions. Districts struggle to fund equipment and maintenance for labs. Costs for teachers included stress and drain on time to keep labs open for students trying to complete projects after class. Two teachers indicated student management issues are challenging. These management issues include students with no interest in clothing construction being forced into classes to fulfill elective requirements, managing students with different skills and abilities who work at various paces, and students who have to share sewing machines. All of the five FCS teachers thought that knowledge of clothing construction was invaluable, critical, or important for a successful career in fashion. Two of the five FCS teachers responded that they had students interested in careers in fashion.

All three of the students in the FCSE program at NMSU who responded to the survey indicated that clothing construction was not offered in their high schools, and consequently, they had no prior exposure to clothing construction before enrolling in university classes. These three students were unanimous in their responses that their first experience with clothing construction class at the university level made them nervous, was intimidating, and an eye-opening experience. All three students expressed their belief in the importance of the knowledge in clothing construction for success in a career in the fashion industry.

Two of FMAD students were able to take clothing construction at the secondary level; therefore, only two students had prior course work in clothing construction. However, 3 of the 4 did take some type of informal course on clothing construction before entering college. This prior experience helped those students in their first college level clothing construction course. Three of the 4 students expressed that a previous course prepared and exposed them to sewing basics and allowed them to negotiate the course content more quickly. All four students unanimously agreed that knowledge of clothing construction was important to achieve success in a career in the field of fashion.

In general, two of the three Fashion Industry Professionals who participated in this study had a preference of hiring candidates with prior clothing construction knowledge/skills. All of the Fashion Industry Professionals indicated that finding employees with appropriate levels of clothing construction skills/knowledge was becoming difficult for their businesses. All of the Fashion Industry Professionals agreed that knowledge in clothing construction was important to their businesses, and for a student's success in a career in the fashion industry.

\section{Conclusion}

In this study, FCS teachers, FCSE and FMAD students along with fashion industry leaders all recognized the importance of clothing construction knowledge for professionals seeking successful careers in both the fashion industry and in FCS education. Due to prior educational experience among students, there are varying degrees of skill and knowledge in clothing construction at the post-secondary level. Some students who did not take classes in clothing construction at the secondary level felt unprepared and less knowledgeable than they would have liked in their university coursework

FCSE students must have training in clothing construction to feel confident enough and prepared to teach clothing construction in the secondary schools. One course at the university level hardly prepares one with the knowledge and training to teach such a complex skill. A lack of training in clothing construction for education students will result in a decline of clothing construction classes being offered at the secondary level. Previously, secondary teachers took multiple courses in clothing construction at the secondary and post-secondary levels and were quite proficient in the skill. Clothing construction skills at the secondary level are being lost as those educators age and leave the profession. With decreasing availability of clothing construction courses at the university level coupled with the lack of courses at the secondary level, the skills and ability to teach clothing construction are being lost as younger teachers who lack the necessary knowledge, skills and training take over FCS programs. A lack of confidence in their abilities to teach will result in the classes being dropped from curriculums.

The importance of taking clothing construction courses in secondary schools was unanimous among Fashion Merchandising students who participated in this study. One student remarked that she chooses FMAD as her major because of the positive experience she had in the clothing construction course at her high school. Students who had the opportunity to take clothing construction classes at the secondary level reported higher levels of confidence in their choice of major and coursework. Other FMAD students who had not taken high school clothing construction classes felt unprepared and intimidated while navigating the coursework at the university, as they compared themselves to classmates with higher skill levels [10].

Finally, Industry Professionals supported the importance of clothing construction knowledge and skills for those seeking a 
career in the fashion industry. Although finding employees with clothing construction knowledge and skills is becoming increasingly difficult, it is a benefit to the employer. Employees with clothing construction knowledge and skills are more likely to be successful in the fashion industry.

Considering the results of this study, it is imperative that clothing construction classes at the secondary level be considered important and should be given more emphasis. Secondary classes provide an introduction to the skill and give students insight into the field of fashion. These classes are an excellent recruiting tool for university fashion programs. Secondary classes provide university students with foundational knowledge and skills and help them negotiate the difficult university classes with ease. Both FCSE and FMAD students are required to take clothing construction classes, and secondary clothing construction classes provide a boost to the students' confidence and abilities. Clothing construction classes at the secondary and university levels provide knowledge and skills necessary for careers in fashion as well as FCS education and are only available at FCS programs.

Participating in clothing construction course work would create a higher level of confidence in students and could lead to an increase in enrollment at both secondary and post-secondary levels. Higher degrees of confidence would be beneficial in reducing the intimidation factor among incoming freshman college students. This knowledge will enhance the opportunities for those with a fashion career path and FCS education paths as candidates with clothing construction skills are more sought after by employers.

We recommend additional research on the impact of clothing construction classes at the secondary level on student retention and success at post-secondary endeavors in the areas of Family and Consumer Sciences Education and Fashion Merchandising and Design. Before clothing construction classes are deleted from curricula, efforts to measure their effectiveness is required.

\section{Acknowledgement}

None.

\section{Conflict of Interest}

Authors declare no conflict of interest.

\section{References}

1. Coffeen KC, Bartley SJ (2019) The case for clothing construction. Journal of Textile Science \& Fashion Technology 2(2): 1-2.

2. Joint Economic Committee, US Congress (2019) The economic impact of the fashion industry.

3. Joint Economic Committee, United States Congress (2016) The economic impact of the fashion industry.

4. Ward D, Lee CL (2005) Assessing clothing construction skills of Family and Consumer Sciences Education student teachers. Journal of Family and Consumer Sciences Education 23(2): 27-31.

5. Brandes K, Garner M (1997) The case for high school clothing construction classes. Journal of Family and Consumer Sciences 89(1): 62-65.

6. Romeo LD, Lee Y-A (2013) Creative and technical design skills: Are college apparel curriculums meeting industry needs? International Journal of Fashion Design, Technology and Education 6(3): 132-140.

7. Ma YJ, Hahn KY (2013) Job expectations, job preference, and learning expectations of apparel merchandising and design college students. International Textile and Apparel Association Annual Conference Proceedings, 188

8. National Association of State Administrators of Family and Consumer Sciences (2018) National standards for family and consumer sciences education 3.0

9. Martindale A, McKinney E (2020) Why do they sew? Women's motivations to sew clothing for themselves. Clothing and Textiles Research Journal 38(1): 32-48.

10. Stotz L, Kane G (2015) Global Market Factsheet. 